\title{
A roadmap for paediatric and neonatal critical care nursing science in Europe: engage, action and impact
}

Tume LN, Ista E, van den Hoogen A, Wielenga J, Latour JM.

Nurs Crit Care. 2015 Sep;20(5):224-6. doi: 10.1111/nicc.12175.

\section{A roadmap for Paediatric and Neonatal Critical Care Nursing Science in Europe: Engage, Action and Impact}

Lyvonne N. Tume ${ }^{1,2}$, Erwin Ista ${ }^{3}$, Agnes van den Hoogen ${ }^{4}$, Joke Wielenga ${ }^{5}$, Jos M. Latour ${ }^{6,7}$

${ }^{1}$ PICU and Children's Nursing Research Unit, Alder Hey Children's NHS, Eaton Road, Liverpool L12 2AP, UK; Email: Lyvonne.tume@alderhey/nhs.uk

${ }^{2}$ University of Central Lancashire, School of Health, Preston, United Kingdom. Preston, PR1 2HE, UK; Email: Intume@uclan.ac.uk

${ }^{3}$ Department of Intensive Care, Erasmus MC-Sophia Children's Hospital, Rotterdam, P.O. Box 2060, 3000 CB, Rotterdam, The Netherlands

${ }^{4}$ Intensive Care Neonatology, Emma Children's Hospital / Academic Medical Centre PO Box 22660, 1100 DD Amsterdam, The Netherlands

${ }^{5}$ Intensive Care Neonatology, Wilhelmina Children's Hospital, University Medical Centre Utrecht, PO Box 85090, 3508 AB Utrecht, The Netherlands

${ }^{6}$ School of Nursing and Midwifery, Faculty of Health and Human Sciences, Plymouth University, Drake Circus, Plymouth, Devon PL4 8AA, United Kingdom; Email: jos.latour@plymouth.ac.uk

${ }^{7}$ School of Nursing and Midwifery, Faculty of Health Science, Curtin University, Kent Street, Bentley, Perth WA 6102, Australia; Email: jos.latour@curtin.edu.au 
Paediatric and neonatal intensive care nursing are both distinct and at times quite different from adult intensive care nursing. An example of the discrepancy between critically ill children and adults in intensive care units is the unique relationship with the parents of critically ill infants and children (Latour and Haines 2007). Unlike carers, partners and spouses of adult intensive care patients, parents are the primary caregiver and are fundamental to the child's existence and recovery. Additionally, for the last 30 years most Paediatric Intensive Care Units (PICUs) and Neonatal Intensive Care Units (NICUs) in northwestern European countries and in the USA have allowed and indeed encouraged 24 hour parental visitation and participation in the care of their critically ill child. This standard practice is still under debate in adult intensive care (Giannini et al. 2014). Other documented differences relate to registered nurse staffing levels and the academic level of education nurses receive to work in these specialities (Baktoft et al. 2001; Aitken et al. 2014, Gill et al. 2011). But even within paediatrics, differences exist between and among PICUs and NICUs in care delivery and organisation (Nipshagen et al. 2002). The NICUs are designed for critically ill preterm neonates and newborns while most PICUs are focussing on a more heterogeneous group of children up to 18 year of age. Beside the implication of difference in treatments in the NICUs and PICUs, generally the care models differ also. The NICUs are mostly directed to the NICAP model (Newborn Individualised Developmental Care and Assessment Program) that was implemented almost two decades ago (Wallin and Erikson, 2009). At the same time the family-centred care model became apparent in the PICUs (Latour, 2005. Thus even though PICU and NICU are distinct from adult intensive care, considerable diversity in PICU and NICU nursing exists across Europe.

The European Society of Pediatric and Neonatal Intensive care (ESPNIC) is a wellknown and respected nurse and physician society for more than 20 years. They revised their structure in 2011 and established themed 'sections' to assist in progressing the society's future. One of these newly created sections is the Nurse Science Section. The aim of this section is to promote and disseminate nursing research in PICU and NICU and engage nurses in the research process across Europe 
(http://espniconline.org/affairs/Pages/Sections.aspx). The membership of this section includes both research-active nurses, nurse scientists and clinical nurses who are interested in research.

The first step in establishing future activities of this section was to define the research priorities for PICU and NICU nurses across Europe. This was undertaken by two Delphi studies in 2012-2013 (Tume et al. 2014, Wielenga et al. 2014). Although there are individual research active PICU and NICU nurses across Europe, undertaking research in areas including pain assessment and scoring , sedation assessment and scoring , withdrawal syndrome, delirium, enteral nutrition, parent satisfaction and safety (Ramelet et al. 2012,2014; Ista et al. 2013,2014; Latour et al. 2007,2011,2013; van Dijk et al. 2001,2009; Tume et al. 2011,2012 ) there are, however, no groups working collaboratively across Europe. In terms of developing nursing science across Europe, researchers and their research may be strengthened if they work collaboratively and across disciplines. It may also enhance their chances of funding success, in agreed priority research areas. This is what the nurse science section is seeking to promote. However, to develop and promote collaborative paediatric and neonatal nursing research across Europe poses a number of challenges. We believe, the diversity in nursing academic education, language barriers, the lack of established research networks and the lack of dedicated nursing academic roles (which allow time for nurses to undertake such work) are the most significant challenges. A recent systematic review has highlighted the generalised poor quality of many European nursing research publications (Richards et al 2014) and a goal of the nurse science section is to improve this within paediatric critical care.

After reaching consensus on priority research topics for PICU and NICU nursing across Europe in 2014 (Tume et al 2014; Wielenga et al 2014), the ESPNIC Nursing Science section has established a five year roadmap to provide focused directions to achieve the goal of achieving collaborative nursing research initiatives. A roadmap is essentially a specific plan, with targets and timelines, with a clear endpoint or goal and is 
standard in project management and business, allowing you to regularly asses your progress and targets (Kappel 2001), and can be used to align organizations in times of predictable change. The key aspects of the ESPNIC nursing science roadmap relate to education, networking, mentoring and enhancing multidisciplinary collaboration within ESPNIC sections, with a view to using more electronic and virtual communications to add to the annual face to face congresses and meetings (http://espniconline.org/affairs/Pages/Sections.aspx; Table 1).

Educational directions are important to support the inconsistency of academic education (for nurses) around clinical research that exists in many European countries. Thus the section has initiated annual clinical research summer schools and runs annual precongress nurse science workshops. In the future this may be extended to web based platforms.

Networking and establishing nurse research support systems are crucial, as many researchers are working on their own, or in silos within their own organisation or country. Having a database of nurse contacts within specific clinical areas and within the field of PICU and NICU is vital for nurse researchers to feel part of a wider group and to be able to extend their research or collaborate in others research in the same area. Research networks have been shown to increase the scholarly activity of nurse researchers (Megel et al. 1998). Effective networks may also assist in the implementation and dissemination of research findings, an increasingly recognised issue in clinical research.

Combined with educational input, mentoring or guidance from senior nurse scientists is vital to the development of effective and confident nurse researchers and in the small field of PICU and NICU nursing, this may not be possible within the individual nurse researchers own institution. E-mentorship across vast geographical locations is now possible and entirely feasible and there are a number of examples of effective international $\mathrm{PhD}$ supervisions, and these relationships can be established through research networks (Byrne \& Keefe 2004). Mentorship is a complex psychosocial process, but can be highly effective. However, in the narrow field of PICU and NICU nursing, establishing a team of 'expert' nurse 
mentors is vitally important to facilitate the development of less experienced nurse researchers, achieved through working on collaborative projects, ideally on agreed priority research topics.

Multidisciplinary research in the field of PICU and NICU is essential. Nurses do not work in isolation from other disciplines in the clinical environment and researchers too, must look to develop an 'ideal team' best suited to their research topic. This is rarely unidisciplinary. Across Europe hierarchical barriers still remain in healthcare, predominantly due to the inequality in nursing academic education compared to medical and other disciplines, but at times also related to gender and the societal value of nursing in different societies. However, as more nurses achieve doctoral level education and take on the leadership for successful research projects and involving other disciplines, these views will change. Nurses need to become active members of multidisciplinary research projects and to demonstrate their unique contribution to these projects (as nurses). Societies, such as ESPNIC, have the ability to promote multidisciplinary collaboration within their sections and this must be encouraged, whilst still maintaining the uniqueness of nursing, and a support network, through a specific nursing section.

We have outlined a roadmap for paediatric and neonatal critical care nursing across Europe achieved through the active engagement of many nursing colleagues and stakeholders. The actions described in the roadmap are our current challenges. A report into nursing research across Europe (Moreno-Casbas 2005), reported that research on nursing issues and the development of nurses researchers remained the preserve of just a few European countries. Ten years on, we believe this is changing as more nurses are educated to doctoral level. With the support of ESPNIC these actions are not challenges but privileges to engage and connect all colleagues around Europe to drive nursing research forward. After all, it will be our critically ill infants, children and their families that benefit from the impact of a European network and collaborative research actions. Engagement, action and impact will be the flow of conducting clinical research to inform evidence-based clinical practice. Join our journey; our PICU and NICU patients and families value the effort and the outcomes. 


\section{References:}

Aitken L, Sloane D, Bruyneel L, van den Heede K, Griffiths, P. Busse R, Diomidous M, Kinnunnen J, Kozka M, Lesaffre E, McHugh M, Moreno-Casbas MT, Rafferty A, Schwendimann R, Scott P, Tishelman C, van Achterberg T, Sermeus W. (2014). Nurse staffing and education and hospital mortality in nine European countries: a retrospective observational study. The Lancet 383:1824-1830.

Baktoft B, Drigo E, Hohl M, Klancar S, Tseroni M, Putzai P. (2001). A survey of critical care nursing education in Europe. CONNECT The World of Critical Care Nursing; 2: 85-87.

Boerlage A, Ista E, Duivenvoorden H, de Wildt S, Tibboel D, van Dijk M. (2014). The COMFORT behaviour scale detects clinically meaningful effects of analgesic and sedative treatment. European Journal of Pain doi: 10.1002/ejp.569.

Byrne M and Keefe M. (2004). Building Research Competence in Nursing Through Mentoring. Journal of Nursing Scholarship 34: 391-396.

ESPNIC http://espnic-online.org/affairs/Pages/Sections.aspx accessed 30 January.2015.

Giannini A, Garrouste-Orgeas M, Latour JM. (2014) What's new in ICU visiting policies: can we continue to keep the doors closed? Intensive Care Medicine 40:730-733

Gill FJ, Leslie GD, Grech C, Latour JM. (2012). A review of critical care nursing staffing, education and practice standards. Australian Critical Care 25:224-237.

Ista E, Troglic Z, Bakker J, Osse R, van Acterberg T, van der Jagt M. (2014). Improvement of care for ICU patients with delirium by early screening and treatment: study protocol of iDECePTIvE study. Implementation Science 9:143.

Ista E, de Hoog M, Tibboel D, Duivenvoorden H, van Dijk M. (2013). Psychometric Evaluation of the Sophia Observation Withdrawal Symptoms Scale in Critically III Children. Pediatric Critical Care Medicine 14:761-769.

Kappel T. (2001). Perspectives on roadmaps: how organizations talk about the future. Journal of Product Innovation Management 18:39-50. 
Latour JM. (2005) Is family-centered care in critical care units that difficult? A view from Europe. Nursing in Critical Care 10:51-53.

Latour JM and Haines C. (2007) Families in the ICU: Do we truly consider their needs, experiences and satisfaction? Nursing in Critical Care 12:173-174.

Latour JM, Duivenvoorden HJ, Hazelzet JA, Tibboel D, and the EMPATHIC study group. (2013) The shortened EMPATHIC-30 questionnaire adequately measured parent satisfaction in pediatric intensive care units. Journal of Clinical Epidemiology 66(9):10451050.

Latour JM, van Goudoever JB, Duivenvoorden HJ, Albers MJIJ, van Dam NAM, Dullaart E, van Heerde M, de Neef M, Verlaat CWM, van Vught EM, Hazelzet JA. (2011) Differences in the perceptions of parents and healthcare professionals on pediatric intensive care practices. Pediatric Critical Care Medicine 12:e211-e215.

Megel M, Langston N, Creswell J. (1998). Scholarly productivity: A survey of nursing faculty researchers. Journal of Professional Nursing 4:45-54.

Nipshagen M, Polderman K, DeVictor D, Gemke R. (2002). Pediatric Intensive Care; results of a European survey. Intensive Care Medicine 28:1797-1803.

Moreno-Casbas T (2005) Nursing Research in Europe - Scoping Report. Funded by European Commission ERA-CARE Network. http://www.isciii.es/ISCIII/es/contenidos/fd-elinstituto/fd-organizacion/fd-estructura-directiva/fd-subdireccion-general-redes-centrosinvestigacion2/fd-centros-unidades2/fd-investen-isciii2/docus/investen NursingResearchInEurope.pdf accessed 16.02.2015

Ramelet A. (2014). In China the use of analgesics and sedation following paediatric cardiac surgery is variable; average pain scores are reported to be good but over-sedation is common. Evidence Based Nursing 17:45-46.

Ramelet A. (2012). Pain assessment in critical care: instrument selection for nonverbal patients. Australian Critical Care: 25:275-277.

Richards D, Coulthard V, Borglin V Reflection review team (2014). The state of European nursing research: dead, alive, or chronically diseased? A systematic literature review Worldviews Evidence Based Nursing. 11:147-55 
Tume L, Carter B, Latten L. (2012). A UK and Irish survey of enteral nutrition practices in paediatric intensive care units. British Journal of Nutrition_109:1304-1322.

Tume L, Baines $P$ and Lisboa P. (2011). The effect of intensive care nursing interventions on the intracranial pressure in paediatric traumatic brain injury. Nursing in Critical Care 16:7784.

Tume L, van den Hoogen A, Wielenga J, Latour J. (2014). An electronic Delphi study to establish pediatric intensive care nursing research priorities in 20 European countries. Pediatric Critical Care Medicine 15: e206-e213.

van Dijk M, de Boer JB, Koot HM, Duivenvoorden HJ, Passchier J, Bouwmeester N, Tibboel D. (2001). The association between physiological and behavioral pain measures in 0- to 3year-old infants after major surgery. Journal of Pain Symptom Management; 22: 600-609.

van Dijk M, Roofthooft DW, Anand KJ, Guldemond F, de Graaf J, Simons S, de Jager Y, van Goudoever JB, Tibboel D. (2009). Taking up the challenge of measuring prolonged pain in (premature) neonates: the COMFORTneo scale seems promising. Clinical Journal of Pain; 25: 607-16.

Wallis L, Eriksson M. (2009) Newborn Individual Development Care and Assessment Program (NIDCAP): a systematic review of the literature. Worldviews Evidence Based Nursing 6:54-69

Wielenga J, Tume L, Latour J, van den Hoogen A .(2014). European neonatal intensive care nursing research priorities: an e-Delphi study. Archives Diseases in Childhood : Fetal Neonatal Edition. 100:F66-71. 
Table 1 Roadmap of the ESPNIC Nurse Science Section, 2015-2020

\begin{tabular}{|c|c|}
\hline Timeframe & Strategy \\
\hline $\begin{array}{l}0-2 \text { years } \\
\text { by } 2017\end{array}$ & $\begin{array}{l}\text { - Continue PICU and NICU Research Summer School } \\
\text { - Continue pre-congress Nurse Science workshops to promote nursing } \\
\text { - Formagement } \\
\text { to facilitate links between ESPNItidisciplinary research } \\
\text { - Electronic access to nurse science meetings } \\
\text { - Database of research active nurses within Europe } \\
\text { Implement consensus statement on pain, sedation and withdrawal in PICU } \\
\text { and NICUs across Europe (including translations) }\end{array}$ \\
\hline $\begin{array}{l}2-4 \text { years } \\
\text { by } 2019\end{array}$ & $\begin{array}{l}\text { - Establish a process of mentorship for individual nurse researchers } \\
\text { - } \text { Develop and link into educational resources to promote research knowledge } \\
\text { - } \text { Formalise links with other research organisations } \\
\text { - Establish a multidisciplinary database of research-active individuals with topic } \\
\text { areas }\end{array}$ \\
\hline $\begin{array}{l}\text { By } 5 \text { years } \\
\text { by } 2020\end{array}$ & $\begin{array}{l}\text { - Establish effective and sustainable research collaborations and working on } \\
\text { collaborative } \\
\text { - Research to target priority areas identified by European Delphi studies in } \\
2013 \\
\text { - Measure effectiveness of implementation of pain, sedation and withdrawal } \\
\text { - } \quad \text { Produce ESPNIC section publications achieved through collaborative studies. }\end{array}$ \\
\hline
\end{tabular}

